\title{
Hiccups in palliative patients: a mini review
}

\section{Introduction}

Hiccups can be defined as involuntary, intermittent, spasmodic contractions of the diaphragm and intercostal muscles, which result in sudden inspirations and end with abrupt closures of the glottis. Hiccups often occur with a frequency of 4 to 60 per minute. ${ }^{1}$ Hiccups are considered persistent when last for more than 48 hours, and intractable when last for more than a month. ${ }^{2}$ Intractable hiccups can occur in 3.9 to $4.5 \%$ of advanced cancer patients in palliative care. ${ }^{3}$ If not properly managed, hiccups can result in exhaustion, fatigue, malnutrition, weigh loss and even death. ${ }^{4}$

\section{Etiology}

Hiccups can result from injuries compromising phrenic and vagus nerves, sympathetic chain and efferent neural connections to the glottis and intercostal muscles., ${ }^{5,6}$ Main causes in palliative care are cerebrovascular accidents, mechanical injuries of central nervous system (tumours, inflammation or traumatism), vagus and phrenic nerve irritation (mediastinal or esophageal masses, pharyngitis, laryngitis), gastric distension or gastroparesis, chemotherapy (especially cisplatin, carboplatin or etoposide), drugs (dopamine agonists, aripiprazole, benzodiazepines, dexamethasone), invasive procedures (pacemakers, central venous catheters), metabolic disorders (hyponatremia, hypocalcaemia, hypokalemia), cardiopathies and psychological causes. ${ }^{7,8}$

\section{Clinical evaluation}

Persistent and intractable hiccups should be carefully evaluated through clinical history, including duration, relationship with meals, gastric symptoms, associated diseases, previous abdominal surgeries, abdominal pain, intestinal constipation, medications (including chemotherapy), abdominal masses or signs of central nervous injuries. Laboratory tests can be useful, as well as computed tomography (thorax, abdomen or brain). Upper endoscopy can help in patients with gastroesophageal symptoms. It is important to emphasize that every exam request should be preceded by individual risks and benefits. During end-of-life stage, tests can be dropped.

\section{Treatment}

If there is a treatable etiology for hiccups, it should be primarily addressed. Surgery or radiotherapy can be performed to manage mediastinal, esophageal or brain masses. Treatment of gastroesophageal reflux or $H$. pylori infection can also provide relief. Medications apparently involved with hiccups should be discontinued wherever possible. In cancer patients in use of dexamethasone, an exchange of the drug for another corticosteroid (methylprednisolone, for example) can help. ${ }^{9-11}$

\section{Non-pharmacological approaches}

Some popular procedures can help in hiccups relief, which include breath holding for a couple of seconds, breath inside a bag, hyperventilation, swallow bread or crushed ice, drink from the far side of a glass, gently rub the eyes, digital ocular globe pressure, belching, stimulation of vagus nerve (pulling knees to chest, for example), fractionated diet, stimulate the uvula with a gauze, or swallow a
Volume 2 Issue 2 - 2018

\begin{abstract}
Ana Lucia Coradazzi, Claudia Luci dos Santos Inhaia, Ricardo Caponero

Advanced Center of Supportive Care and Integrative Medicine, Hospital Alemão Oswaldo Cruz, Brazil

Correspondence: Ana Lucia Coradazzi,Advanced Center of Supportive Care and Integrative Medicine, Hospital Alemão Oswaldo Cruz, Rua Victor Burjato, 5I, Jaú, São Paulo, Brazil, Tel 55 14 362।-3137, Email ana.coradazzi@terra.com.br
\end{abstract}

Received: February 14, 2018| Published: March 16, 2018

tablespoon with xylocaine gel plus sugar and lemon juice., ${ }^{3,12-18} \mathrm{~A}$ recent systematic review about the use of acupuncture for persistent hiccups concluded that there are not high quality studies to support its indication, but available results are encouraging. ${ }^{19-23} \mathrm{~A}$ small study demonstrated efficacy of vinegar nasal instillation in advanced cancer patients with persistent hiccups. ${ }^{24}$ Descriptions of behavioral conditioning, hypnosis and even prayer can also be found, but there is no strong evidence for support their indication.

\section{Pharmacological approaches}

Lack of consistent data about pharmacological therapy enhances its use only when etiology is not manageable and non-pharmacological procedures failed. Chlorpromazine is the most popular drug, although there are just a few studies available. Recommended dose of chlorpromazine is $25-50 \mathrm{mg}$ orally every $6-8$ hours for 3 to 7 days. Parenteral use of chlorpromazine $(25-50 \mathrm{mg}$ intravenously or intramuscularly) can be more effective than oral administration, but hypotension is a major problem in this approach, which should be minimized through preloading the patient with $500-1000 \mathrm{ml}$ of intravenous fluid. In any case, chlorpromazine is often associated to drowsiness, hypotension and dizziness, even when given orally, and should be avoided in elderly. ${ }^{25,26}$ If chlorpromazine failed, gabapentin can be considered (recommended dose $300-1200 \mathrm{mg}$ orally/24 hours), with hiccups relief reported in $66.7-88.4 \%$ of patients. ${ }^{3,16,18,27}$ If there is associated gastric distension, metoclopramide can be useful (10-40 mg orally every 8 hours for 7 to 10 days), alone or in combination with proton-pump inhibitors. ${ }^{28-31}$

Baclofen was evaluated in small studies involving patients with previous use of chlorpromazine, metoclopramide and/or diazepam. A significant improvement in hiccups frequency and intensity was observed, but drowsiness and dizziness were reported. Association of baclofen and olanzapine was also described, with promising results. ${ }^{17,32-35}$

\section{Invasive procedures}

Surgical phrenic nerve ablation has been advocated for intractable cases that are unresponsive to other treatment, as well as phrenic blocked with local anesthetic. This drastic approach may be associated 
with considerable morbidity and is not universally successful. So, temporary blockade as upfront strategy is advisable. Electrical stimulation of phrenic nerve (with a respiratory pacemaker) had also been described as effective. ${ }^{7,36-39}$

\section{Acknowledgements}

We are deeply grateful to all the members of our Palliative Care Best Practices Team, at Hospital Alemão Oswaldo Cruz, for all the support and tireless work. We would like also to thank the members of the Bioethics Committee at our institution for helpful and devoted guidance.

\section{Conflict of interest}

None.

\section{References}

1. Krakauer E, Zhu A, Bounds B. Case records of the Massachusetts General Hospital. Weekly clinicopathological exercises. A 58-yyearold man with esophageal cancer and nausea, vomiting, and intractable hiccups. N Eng J Med. 2005;352(8):817-825.

2. Hansen B, Rosenberg J. Persistent postoperative hiccups: a review. Acta Anaesthesiol Scand. 1993;37(7):643-646.

3. Porzio G, Aielli F, Verna L, et al. Gabapentin in the treatment of hiccups in patients with advanced cancer: a five-year experience. Clin Neuropharmacol. 2010;33(4):179-180.

4. Howard R. Persistent hiccups. BMJ. 1992;305(6864):1237-1238.

5. Takahashi T, Murata T, Omori M, et al. Successful treatment of intractable hiccups with serotonin (5-HT)1A receptor agonist. J Neurol. 2004;251(4):486-487.

6. Hongliang X, Xuemei C, Shizhao H, et al. Acupuncture and cupping for treatment of hiccup in cases of cerebrovascular accident. $J$ Tradit Chin Med. 2006;26(3):175-176.

7. Lewis J. Hiccups: causes and cures. J Clin Gastroenterol. 1985;7(6):539552 .

8. Chang FY, Lu CL. Hiccup: mistery, nature and treatment. $J$ Neurogastroenterol Motil. 2012;18(2):123-130.

9. Kang J, Hui D, Kim MJ, et al. Corticosteroid rotation to alleviate dexamethasone-induced hiccup: a case series at a single institution. $J$ Pain Symptom Manage. 2012;43(3):625-630.

10. Lee G, Oh SY, Kang MH, et al. Treatment of dexamethasone-induced hiccup in chemotherapy patients by methylprednisolone rotation Oncologist. 2013;18(11):1229-1234.

11. Go S, Koo DH, Kim ST, et al. Antiemetic corticosteroid rotation from dexamethasone to methylprednisolone to prevent dexamethasoneinduced hiccup in cancer patients treated with chemotherapy: randomized, single-blinded, crossover phase III trial. Oncologist. 2017;22(11):1354-1361.

12. Nabal Vicuña M, Guanter L. Therapeutic approach of difficult symptoms in palliative care. Med Pal. 2002;9:96-101.

13. Nagayama T, Kaji M, Hirano H, et al. Intractable hiccups as a presenting symptom of cerebellar hemangioblastoma: case report. $J$ Neurosurg. 2004;100(6):1107-1110.

14. Todisco T, Todisco C, Bruni L, Donato R, et al. Chin stimulation: a trigger point for provoking acute hiccups. Respiration. 2004;71(1):104.
15. Perdue C, Lloyd E. Managing persistent hiccups in advanced cancer 2 : treatment. Nurs Times. 2008;104(35): 20-21.

16. Tegeler M, Baumrucker S. Gabapentine for intractable hiccups in palliative care. Am J Hosp Palliat Care. 2008;25(1):52-54.

17. Turkyilmaz A, Eroglu A. Use of baclofen in the treatment of esophageal stent-related hiccups. Ann Thorac Surg. 2008;85(1):328-330.

18. Marinella M. Diagnosis and management of hiccups in the patient with advanced cancer. J Support Oncol. 2009;7(4):122-127.

19. Schiff E, River Y, Oliven A, et al. Acupuncture therapy for persistent hiccups. Am J Med Sci. 2002;323(3):166-168.

20. Ge A, et al. Acupuncture treatment for persistent hiccups in patients with cancer. J Altern Complement Med. 2010;16(7):811-816.

21. Moretto E, Wee B, Wiffen PJ, et al. Interventions for treating persistent and intractable hiccups in adults (review). Cochrane Database Syst Rev. 2013;(1):Cd008768

22. Choi T, Lee M, Ernst E. Acupuncture for cancer patients suffering from hiccups: a systematic review and meta-analysis. Complement Ther Med. 2012;20(6):447-455

23. Chang C, Chang ST, Lin JC, et al. Resolution of intractable hiccups after near-infrared irradiation of relevant accupoints. Am J Med Sci. 2006;332(2):93-96.

24. Kako J, Kobayashi M, Kanno Y, et al. Intranasal Vinegar as an Effective Treatment for Persistent Hiccups in a Patient With Advanced Cancer Undergoing Palliative Care. J Pain Symptom Manage. 2017;54(2):e2-4.

25. Friedgood C, Ripstein C. Chorpromazine (thorazine) in the treatment of intractable hiccups. J Am Med Assoc. 1955;157(4):309-310.

26. Polito N, Fellows S. Pharmacologic interventions for intractable and persistent hiccups: a systematic review. J Emerg Med. 2017;53(4):540549 .

27. Moretti R, Torre P, Antonello RM, et al. Gabapentin as a drug therapy of intractable hiccup because of vascular lesion: a three-year follow-up. Neurologist. 2004;10(2):102-106.

28. Madanagopolan N. Metoclopramide in hiccup. Curr Med Res Opin. 1975;3(6):371-374.

29. Hiyama T, Yoshihara M, Tanaka S, et al. Effectiveness of prokinetic agents against diseases external to the gastrintestinal tract. J Gastroenterol Hepatol. 2009;24(4):537-546.

30. Wang T, Wang D. Metoclopramide for patients with intractable hiccups: a multicentre, randomised, controlled pilot study. Intern Med J. 2104;44(12a):1205-1209.

31. Kohse E, Hollmann MW, Bardenheuer HJ, et al. Chronic hiccups: an underestimated problem. Anesth Analg. 2017;125(4):1169-1183.

32. Walker P, Watanabe S, Bruera E. Baclofen, a treatment for chronic hiccup. J Pain Symptom Manage. 1998;16(2):125-132.

33. Ramirez F, Graham D. Treatment of intractable hiccup with baclofen: results of a double-blind randomized, controlled, cross-over study. Am J Gastroenterol. 1992;87(12):1789-1791.

34. Guelaud C, Similowski T, Bizec JL, et al. Baclofen therapy for chronic hiccup. Eur Respir J. 1995;8(2):235-237.

35. Thompson A, Ehret Leal J, Brzezinski W. Olanzapine and baclofen for the treatment of intractable hiccups. Pharmacotherapy. 2014;34(1):e48 . 
36. Dobelle W. Use of breathing pacemakers to suppress intractable hiccups of up to thirteen years duration. ASAIO J. 1999;45(6):524-525.

37. Payne B, Tiel RL, Payne MS, et al. Vagus nerve stimulation for chronic intractable hiccups. Case report. J Neurosurg. 2005;102(5): p.935-937.

38. Longatti P, Basaldella L, Moro M, et al. Refractory central supratentorial hiccup partially relieved with vagus nerve stimulation. J Neurol Neurosurg Psychiatry. 2010;81(7):821-822.
39. Schulz-Stübner S, Kehl F. Treatment of persistent hiccups with transcutaneous phrenic and vagal nerve stimulation. Intensive Care Med. 2011;37(6):1048-1049. 